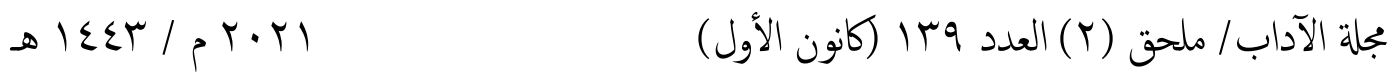

Metaphor and its Semantic Representations in the Contemporary Iraqi Theatrical Text

Hassanein Ali Hilo AI -Zaidi, master's degree Student

Hsnyn1696@gmail.com

Asst. Prof. Harith H. Abdalyama, PHD

University of Baghdad/ College of Fine Arts/ Theatrical Arts

DOI: $\underline{10.31973 / a j . v 3 i 139.2301}$

\begin{abstract}
:
Language can be communicated and expressed through semantic indications of signs to create a concept that expands meaning. It enables to make style of various linguistic patterns as language is a literary subject. So, the theatrical field is among the most productive and the most fields that overlap ideas and could expand meanings and indications. Metaphor is one of the important rhetorical concepts that the writers use to keep pace with the development and comprehensive changes in life since theater is a fertile field for the process of functioning metaphor and giving the ability to expand the meaning, form interpretive connotations based on overlapping within the structure of the theatrical text. The researcher tries here to throw light on the most important representations of metaphor in the Iraqi theatrical text. This work includes four sections. Section one includes methodological construction, research problem, how we need it, aiming to identify metaphor and its representations in the Iraqi theatrical text, as well as the limits of the research and defining terminology. The second chapter included two topics: the concept of metaphor, and metaphor in the theatrical text, the chapter concluded with theoretical framework indicators. The third chapter covers the research procedures that include the research community as the researcher relied on the indicators of a theoretical framework with the sample analysis, chosen intentionally. Chapter four introduces research results, conclusions, a list of sources and references.
\end{abstract}




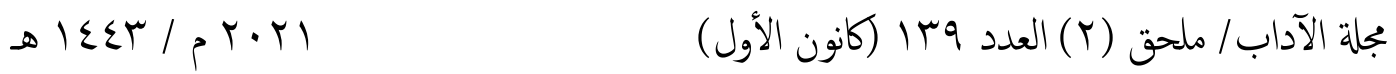

الاستعارة وتمثلاتها الالالية في النص المسرحي العراقي المعاصر

أ.م.د. حارث حمزة عبد اليمة

جامعة بذاد / كلية الفنون الجميلة

الفنون المسرحية
الباحث حسنين علي حلو الزيلي

جامعة بغداد / كلية الفنون الجميلة

الفنون المسرحية

Hsnyn1696@gmail.com

(مُلَخَّصُ الَبَحث)

تكون للغة القدرة على التواصل والتعبير بواسطة المفاهيم الدلالية من العلامات من اجل خلق مفهوم يتسع بها المعنى، ويكون اسلوبه الخاص بمختلف من الانماط اللغويـة، باعتبار ان اللغة هي موضوع ادبي، وبهذا يكون المجال المسرحي بين اخصب واكثر المجالات التي تكون تداخل للأفكار والقدرة على التوسع بالمعاني والدلالات، فتعتبر الاستعارة من المفاهيم البلاغية المهمة التي يتخذها الكتاب لمواكبة التطور والمتغيرات الشاملة في الحياة ، فالمسرح كون مجال خصب لعملية توظيف الاستعارة واعطاء القدرة على التوسـع بالمعنى، لتكوين دلالات تأويلية قائمسة داخل بنية النص المسرحي، وهنا يحاول الباحث تسليط الضوء على اهم تمثلات الاستعارة في النص المسرحي العراقي وقد تضمن البحث اربع فصول: الفصل الاول الاطـار المنهجي، الذي تتـاول مشكلة البحث واهميته والحاجـه اليه، وهدف البحث المتمثلة التعرف على الاستعارة وتمثلاتها في النص المسرحي العراقي، فضـلا عن حدود البحث، وتحديد المصـلحات، وشـمل الفصـل الثاني: فتكـون مـن مبحثين الاول: مفهوم الاستعارة، والثاني الاستعارة في النص المسرحي، لينتهي الفصل بمؤشرات الاطار النظري، امسا الفصل الثالث، فقد شمل اجراءات البحث، من خلال تحديد مجتمع البحث، اذ اعتمد الباحث على مؤشرات الاطـار نظري بمعليه تحليل العينة، المختارة بالشكل القصدي، كمـا ضم الفصل الرابع النتائج والاستتتاجات فضلا عن المصادر والمراجع. المقدمة:

تأتي الاستعارة من خلال ما يتم ادراكه على انها من أكثر الصيغ الجوهريـة التي تتكون في اللغـة بصـورة مجازيـة، واللغـة المجازيـة هو بمثابـة اعطاء للأشياء معاني تكون بداخلها ابعاد وتصورات أكثر بلاغية، وتكون هذه التحولات نتيجة ما يتكون في الشكل صور ذهنية او بصرية لدى القارئ 
الفصل الاول / الإطار المنهجي

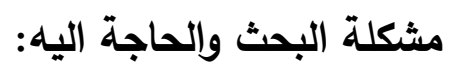

أن اللغة منذ تكوينها اعتبرت مستودع من أهم المفاهيم والاصناف، فمن دونها يصبح التفكير العميق محدد، فان اغلب النظريات تعتبر اللغة ما هي الا تعبير عن الفكر الابداعي،

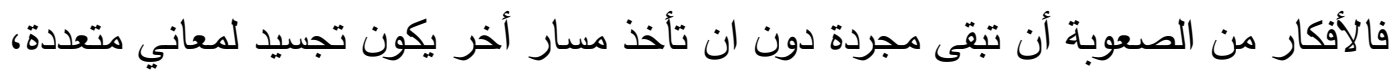

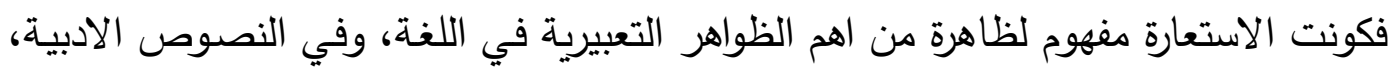

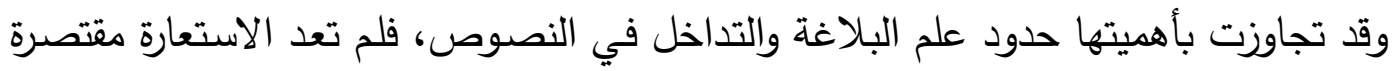

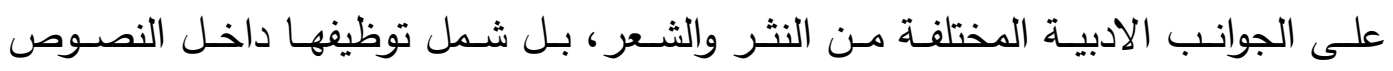
المسرحية بشكل الدلالي تتسجم مع مقومات العمل الفني، وتعطي بعملية اشتغالها التوسعة التهلة

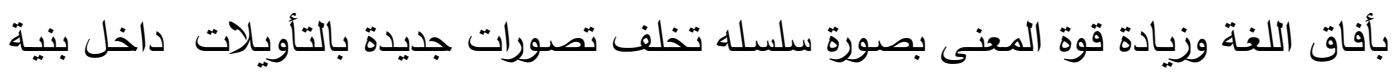

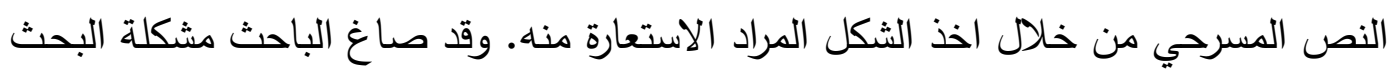

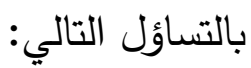
ما مفهوم الاستعارة وتمثلاتها الدلالية بالنص المسرحي العراقي؟

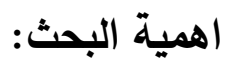
تتجلى اهمية البحث بوصفها محاولة للكثف عن مفهوم الاستعارة في النص المسرحي العراقي لتفيد المهتمين بمجال الفنون المسرحية، والدارسين بمجال النقد المسرحي.

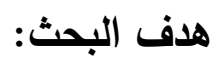

1- التعرف على الاستعارة وتمثلاتها في النص المسرحي العراقي المعاصر •

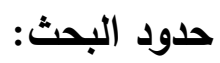

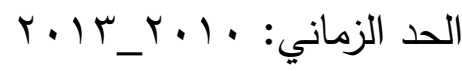

$$
\begin{aligned}
& \text { الحد المكاني: العراق الحماتي }
\end{aligned}
$$

الحد الموضوعي: دراسة مفهوم الاستعارة في النص الدسرحي العراقي.

تحديد مصطلحات:

الاستعارة: لغة: لقد جاء على لسان العرب (لابن منظور) عن المعاني التي يمكن أن

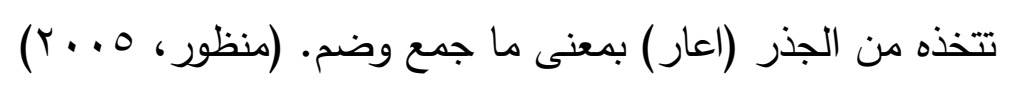

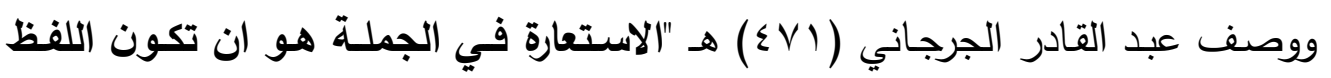

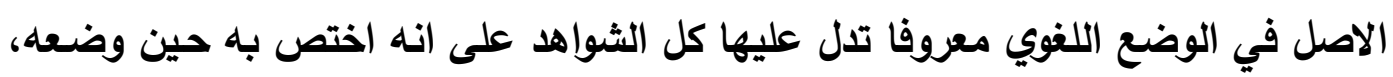

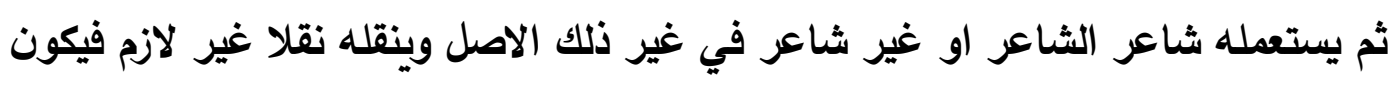
هناك كالعارية". (الجرجاني ع.ع. 
اصطلاحا: ما اكتفى فيها بالاسم المستعار عن الاصلي، ونقلت العبارة فجعلت مكان غيرها وملاكها بقرب التشبيه ومناسبة المستعار للمستعار له، وامتزاج اللفظ بالمعنى حتى لا يوجد

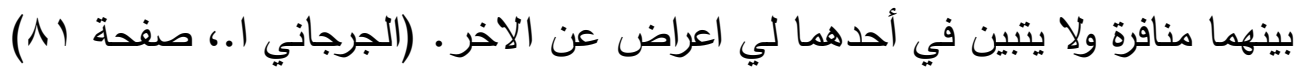

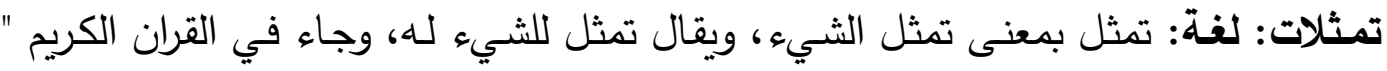

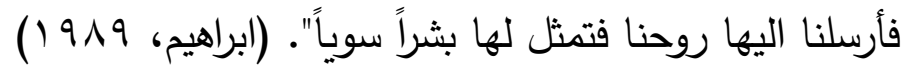

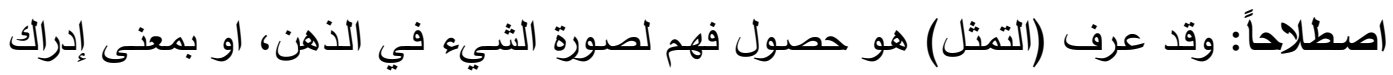

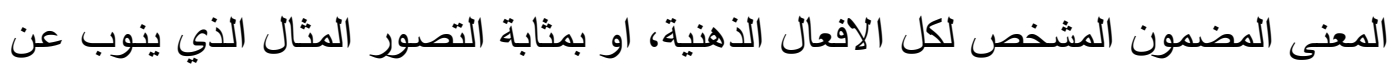

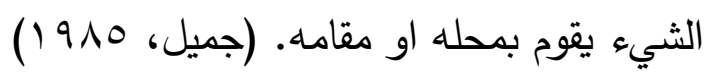

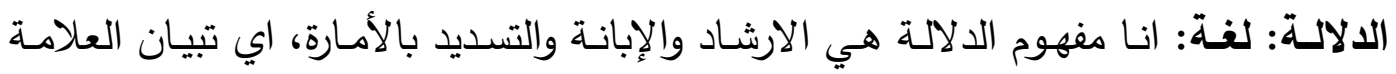

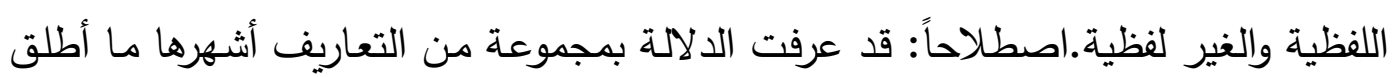

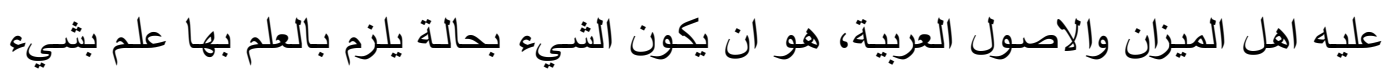

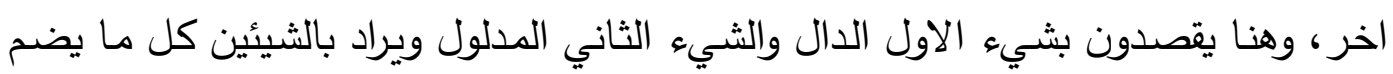

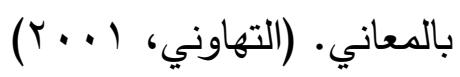
التعريف الاجرائي: (الاستعارة) عملية توظيف للأفكار وتضمينها، والخروج بمعاني أكثر قوة واشمل بصورة بلاغية محكمة تدعم الوجود الاصلي لبنية الافكار .

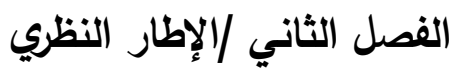
المبحث الاول

Metaphor: مفهوم: الاستعارة

تتركز الاستعارة بشكل كبير في البنية الكلام للإنسان ، كما ان لدفهوم الاستعارة تشكيلاً

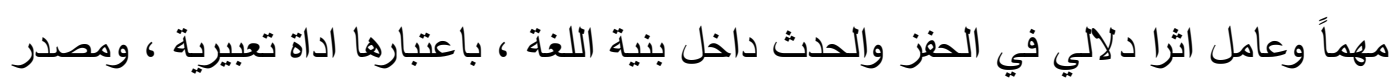

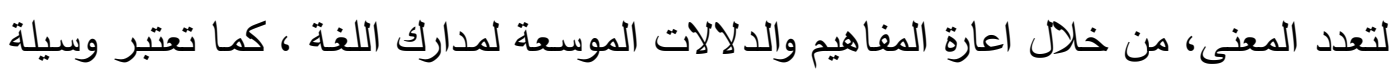

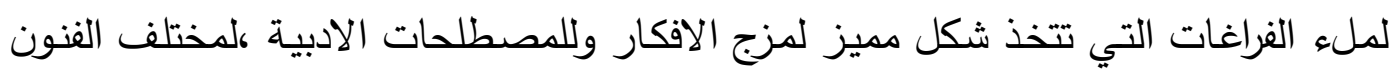

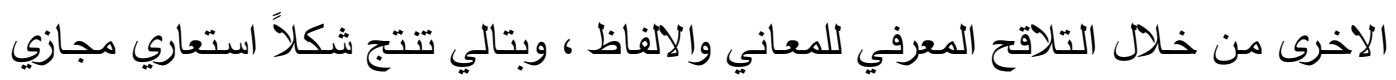

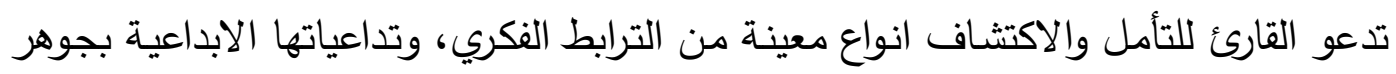

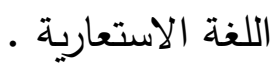
تعرف الاستعارة من العارية وهي معروفة بمعنى اعار او رفع، فتتخذ من الكلام استعارة

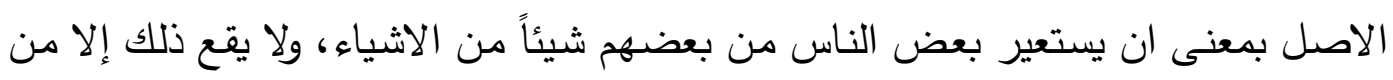

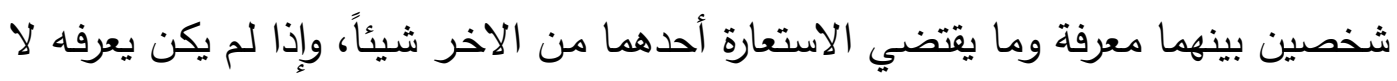

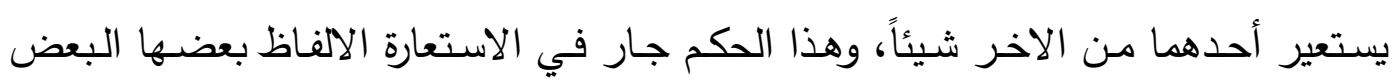

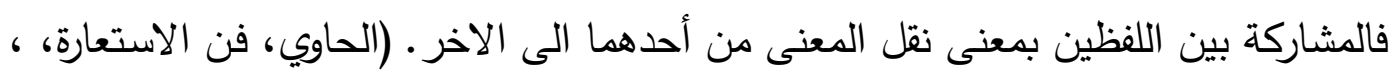




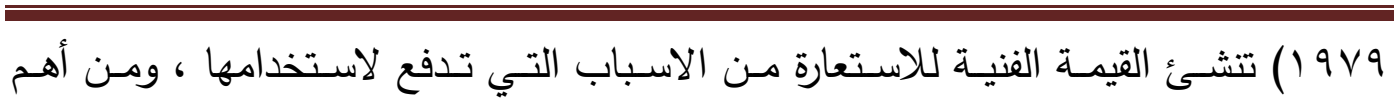

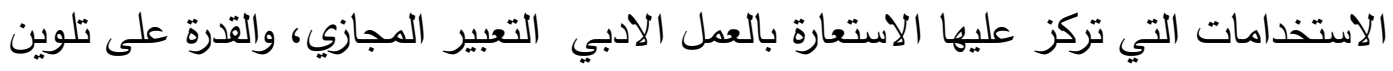

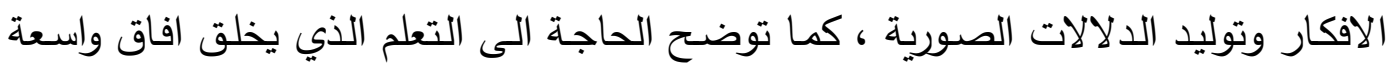

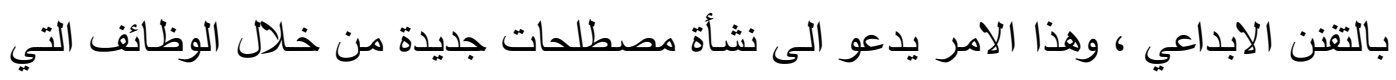

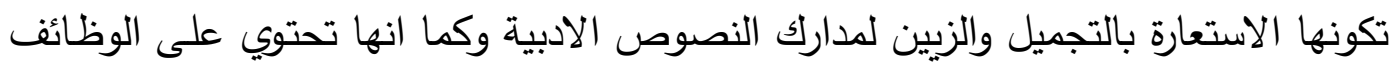

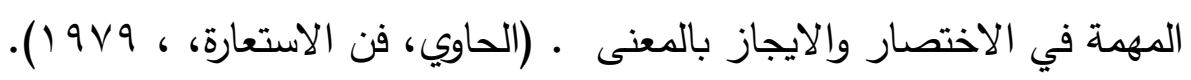

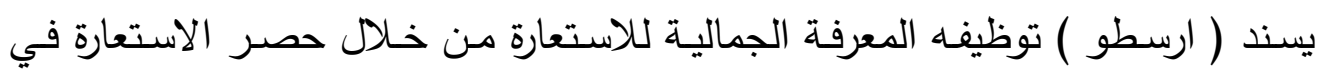

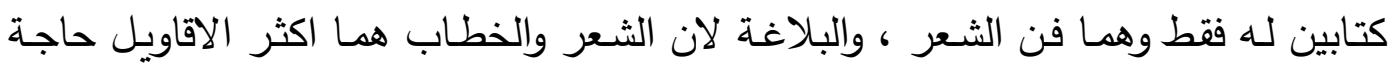

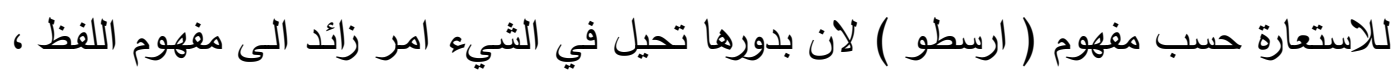

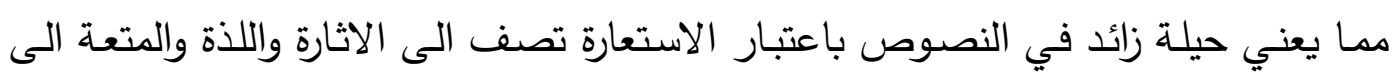

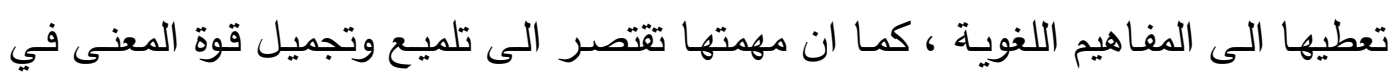

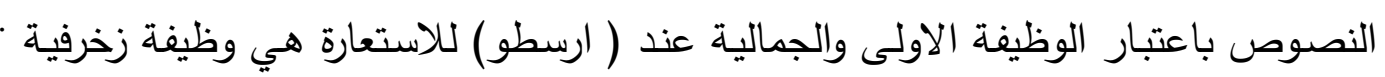

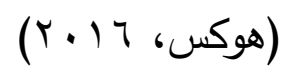
يرى الباحث ان اشتغال الاستعارة على زيادة قوة المعنى تشتغل من خلال الاخذ الأفكار

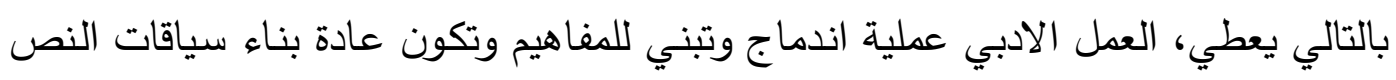

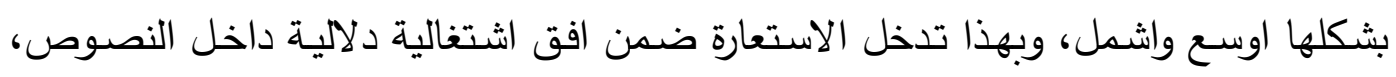

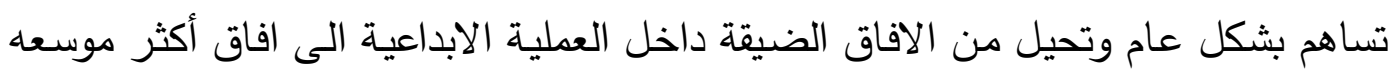
للمعاني المستعيرة. تدخل الاستعارة حيز كبير داخل الإبعاد الفلسفية فيذكر الفيلسوف (نيتشيه) ويطرح

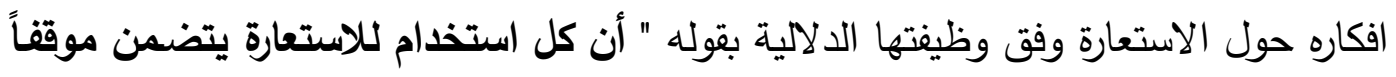

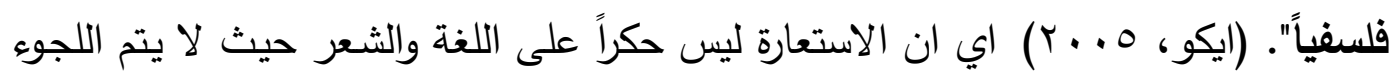

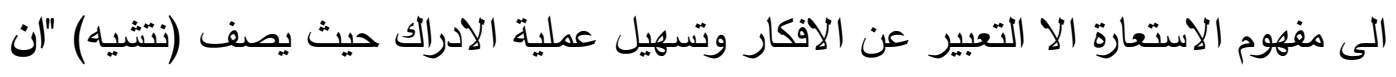

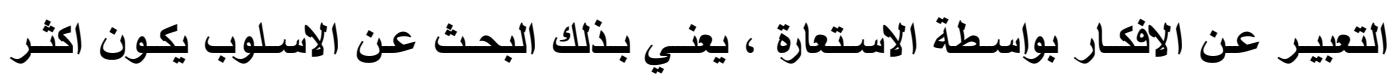

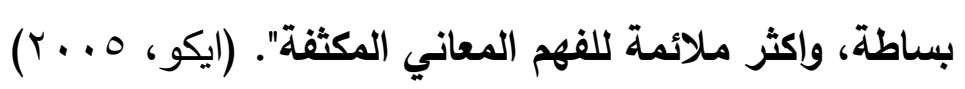

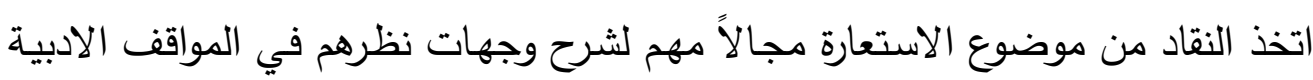

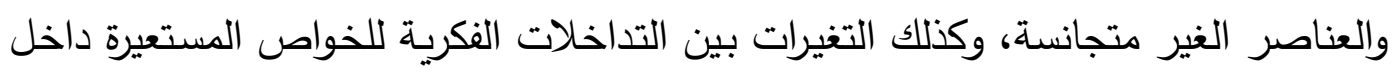
السياقات النصوص، حيث تبين الاستعارة وسيلة من الوسائل الربط، وكذلك تعد مفهوم

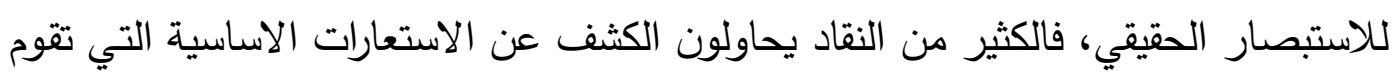

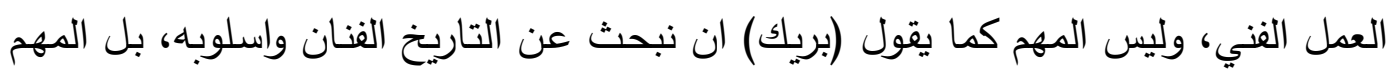


ان نبحث مـا يعطيه التكرار بعض الصور في الاعمال الادبية، وبذلك نحصل على اهم الدلالات اللغوية الخصبة “" (الحاوي، فن الاستعارة، ، 9 ل ( ) )

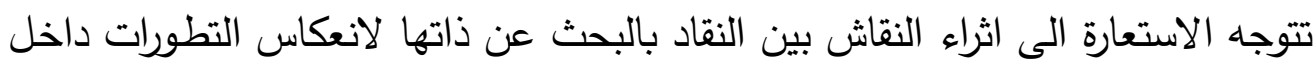

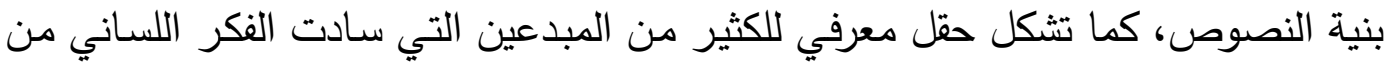
خلال اختزال الاستعارة للطبيعة اللغوية، "اي احلال كلمـة محل اخرى على اسـاس التشـابه

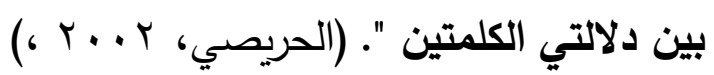

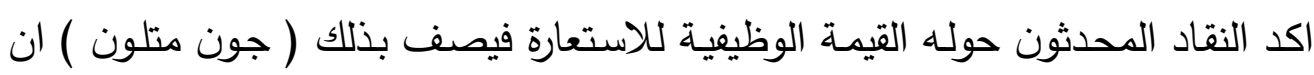
الاستعارة تبدء من خـلال نشـاط غريزي عبره انشطة العقل، فمن خلالها يمكنتا المحاولـة الاكتشاف الواقع وتنظيم التجارب الإنسانية، كما انها وسيلة التي يمكن عن طريقها الفصل

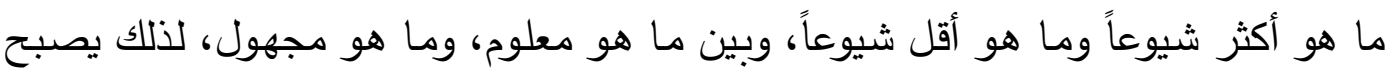

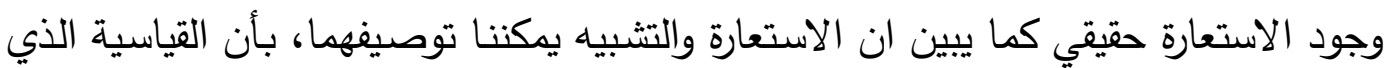

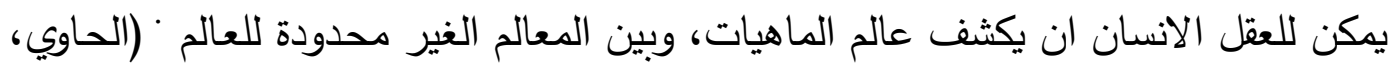

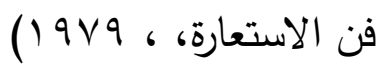
ان التطور الفكر الانساني للنشاط الاستعاري حيث يقوم على مفهوم الاستبدال والنقل،

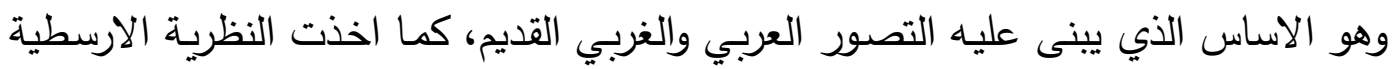

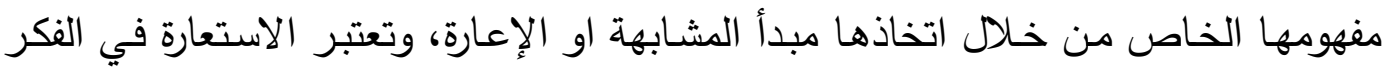

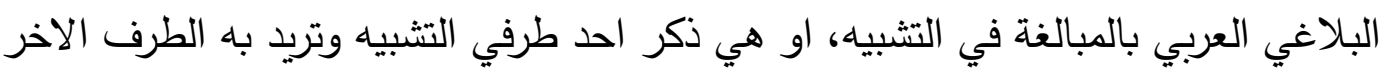

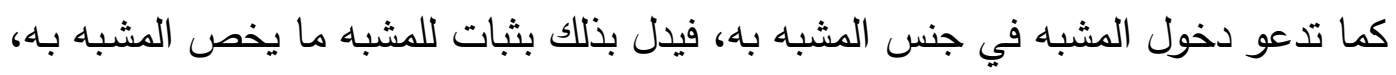

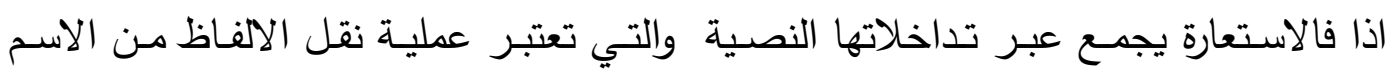

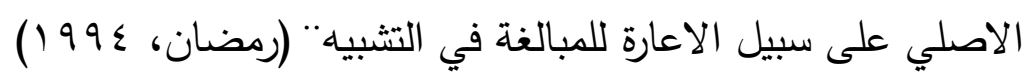

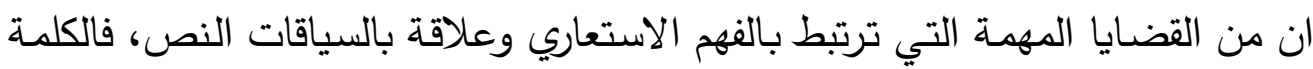

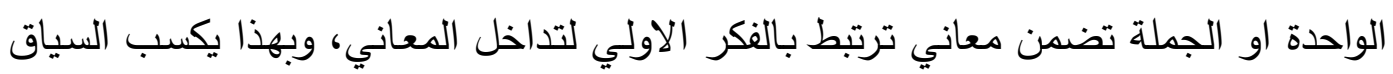

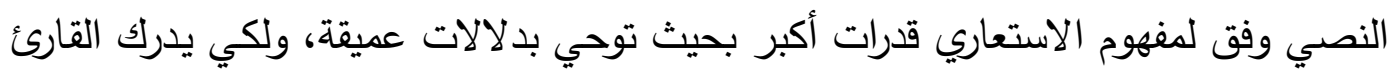

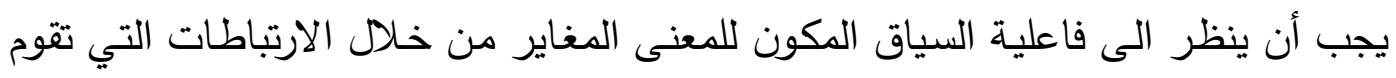

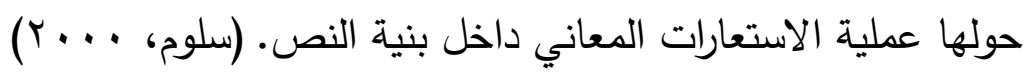
البحث الثاني r - الاستعارة في النص المسرحي: ينشـا النص المسرحي في داخله عمليات من الاجتهاد الابداعي والفني ليكون بذلك لكس

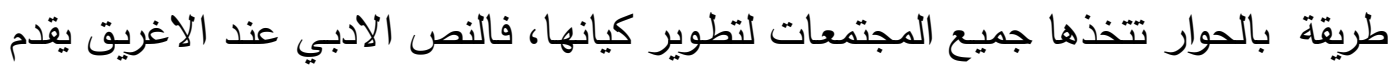

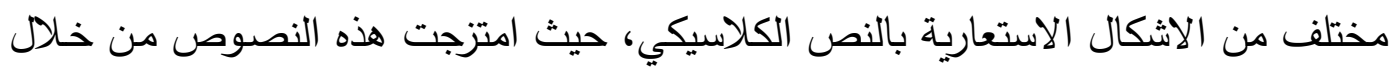


اسـتعارات للطقـوس الثـعائر المتكونــة في الماضـي، فقـد قدم أشـهر كتـاب الكلاسـيكية اسخيلوس، وسـوفوكلس، ويبوربيدس الكثير من النصوص المسرحية كونت خصوصيتها

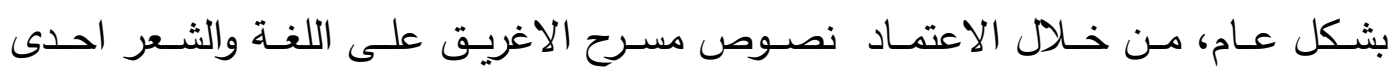

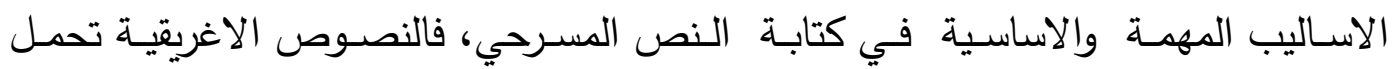

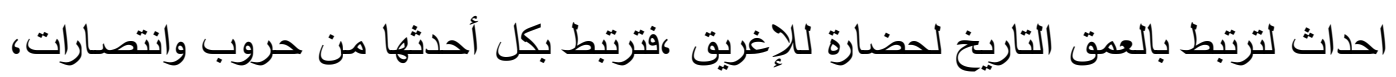

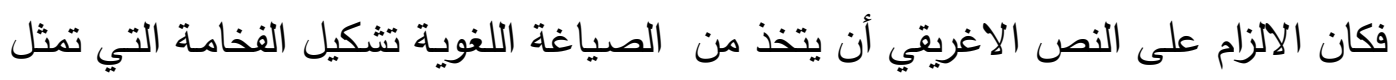

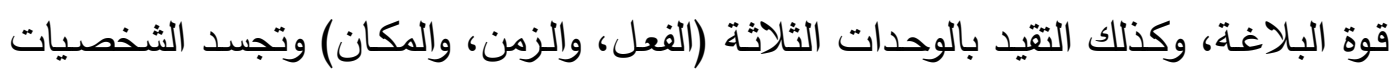

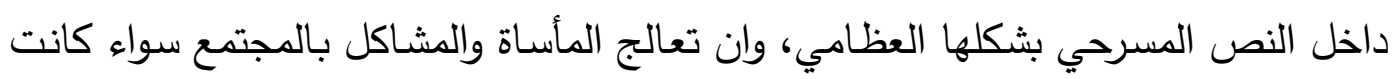

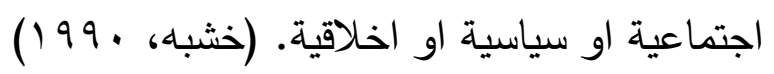

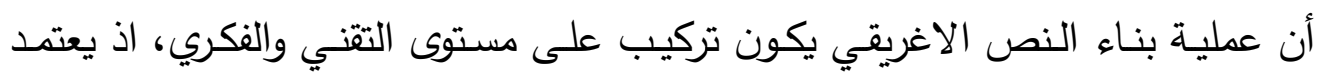

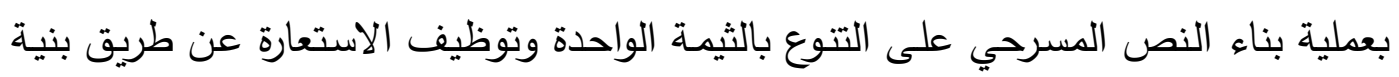

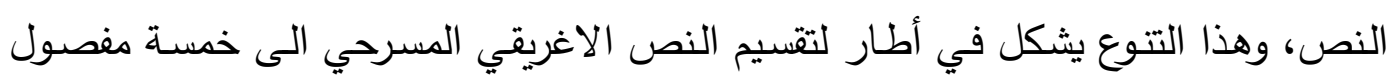

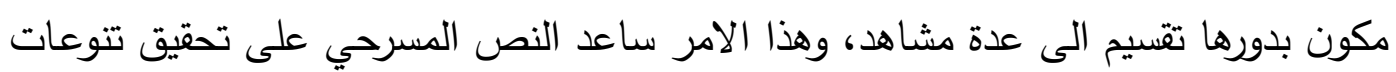

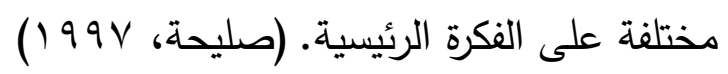

يرى الباحث ان النص الكلاسيكي يكون عملية توظيف لدفهوم الاستعارة من خلال

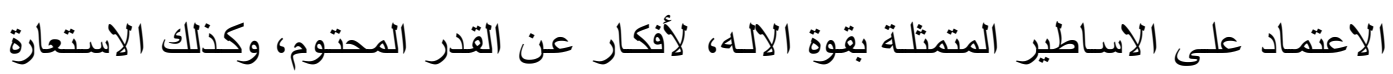

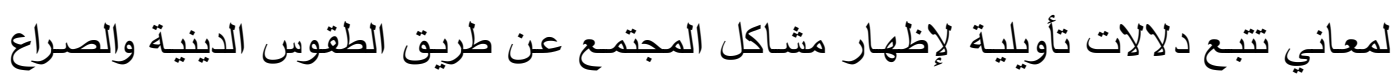

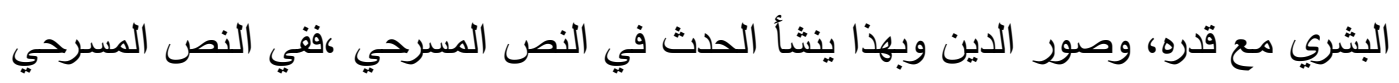

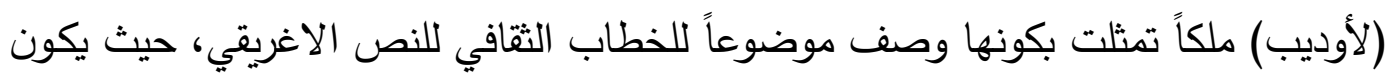

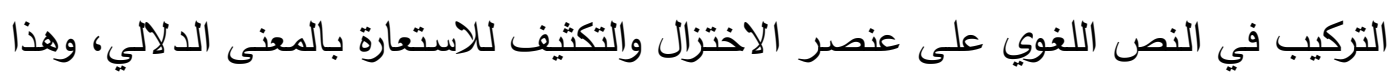

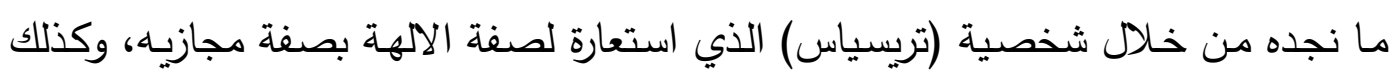
يمثل صورة صراع شخصية (اوديب) مع القدر وظيفة استعارة للمعنى الايمان.

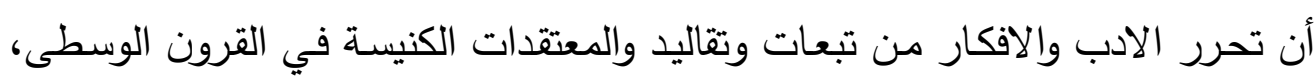

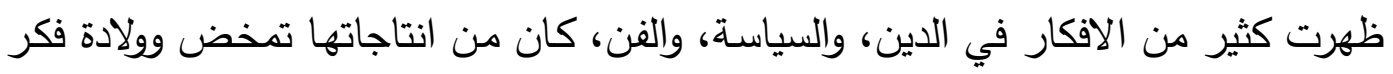

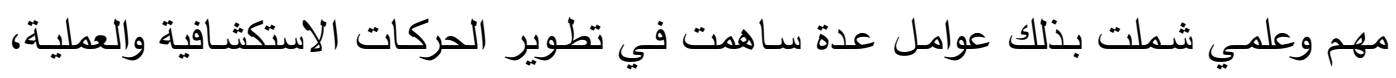

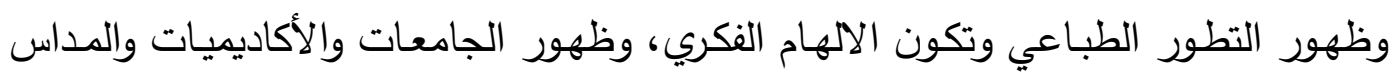

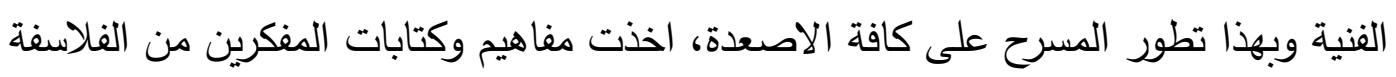

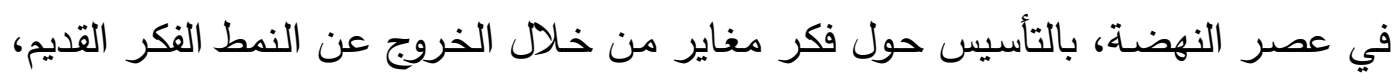

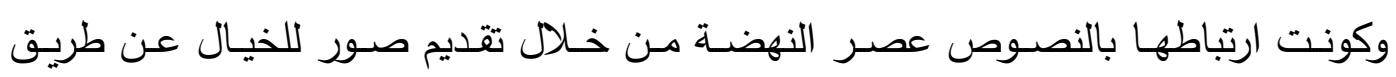

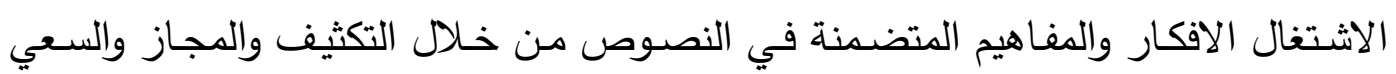




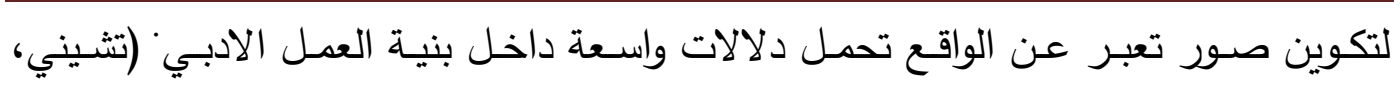

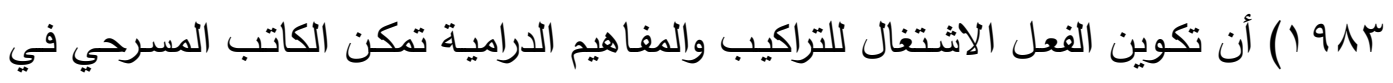

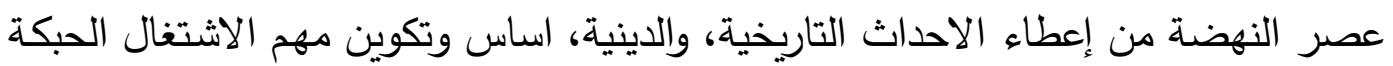

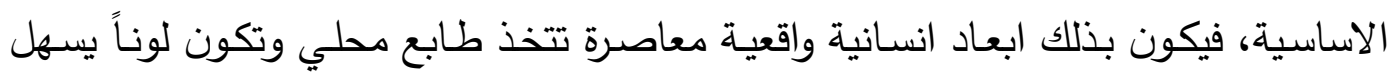

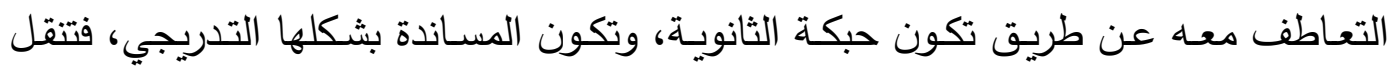

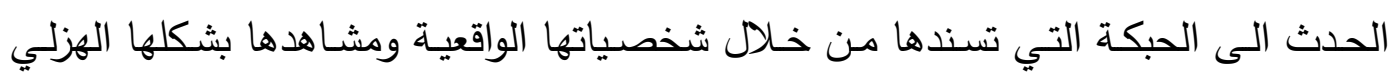
وبهذا لم تعد الاحداث الدينية والتاريخية مهمه في حد ذاتها، وانما يكون تأثيره على الحياة الانسانية العادية المعاصرة، كما في شخصية دكتور فأوست، وشخصية الوهم (لموليير)

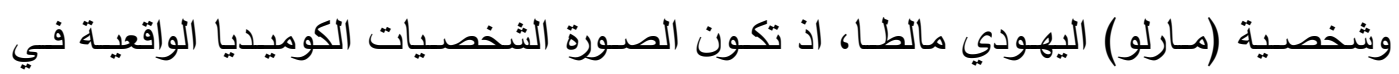

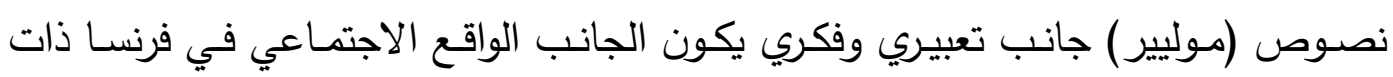

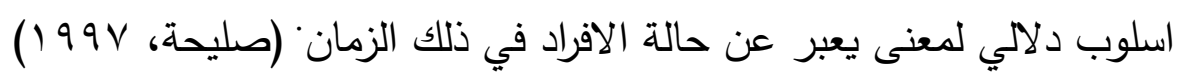
ان نصوص التي تكونها شخصيات (شكسبير) تكون تداخل بين الواقع والخيال، ويكون

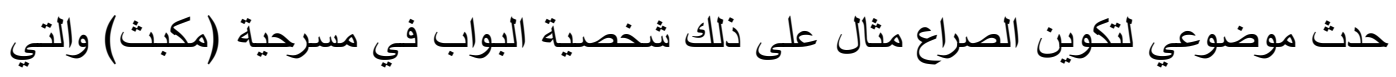

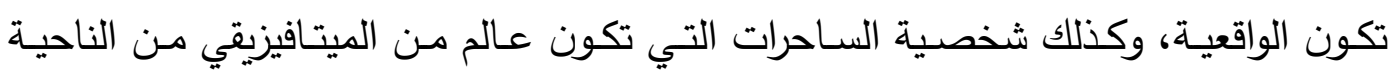

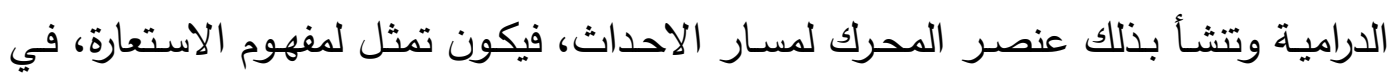

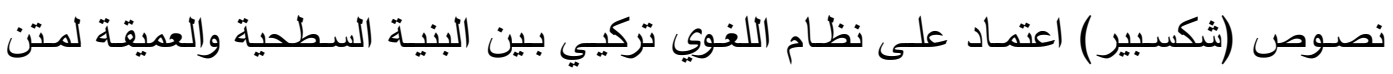

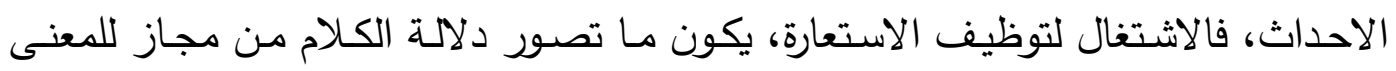

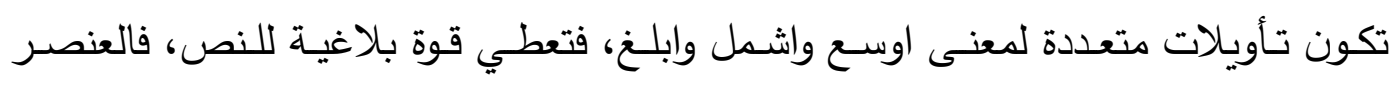

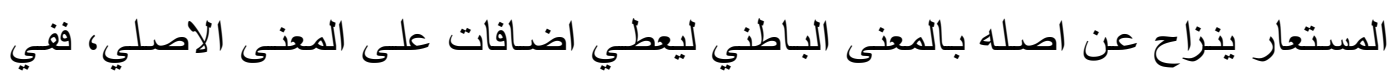

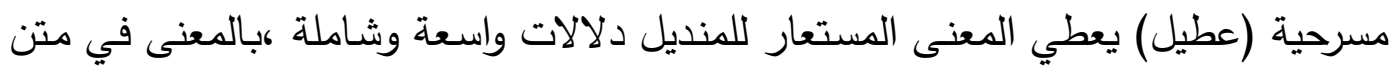
المسرحية، فيرتبط المنديل لمعنى استعاري لعذريـة المرأة التي ترتبط بـالأعراف والتقاليد.

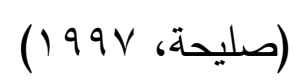

كون (شكسبير) من خلال صياغة الحوار الدراماتيكي لتضمين الصور الشعرية، حيث

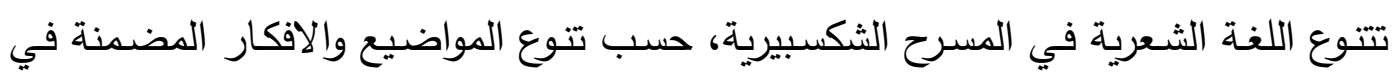

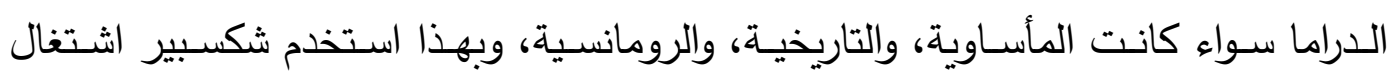
تضمين لجنس الثعر الدرامي فأقترب من اللغة الرفيعة المكون لتسلسل الحوارات، يكون

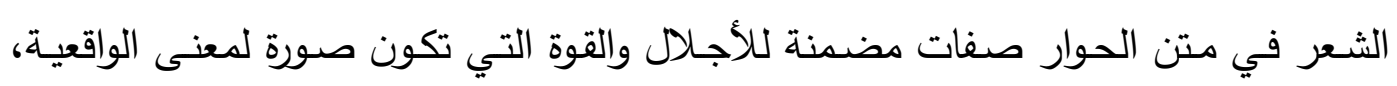
يقابل شكسبير الشعر باللغة تضمين جنس النثر فلهو النصيب الاخر فمن خـال اشتغال

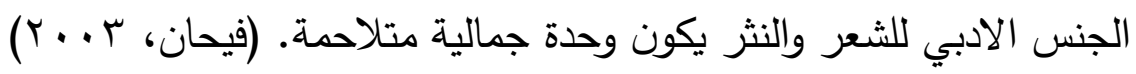


حيث يميل (شكسبير) الى حصر النثر بالموضوعات الواقعية والهزلية، يستعير شكسبير

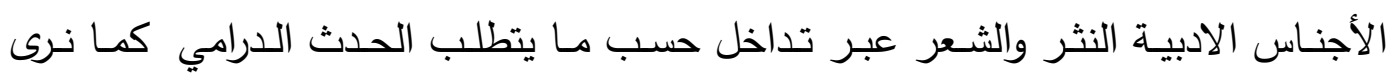
بمسرحية (هاملت) عندما يمثل دور المجنون يستعير في حديثه النثر وعندما يكون حديثه

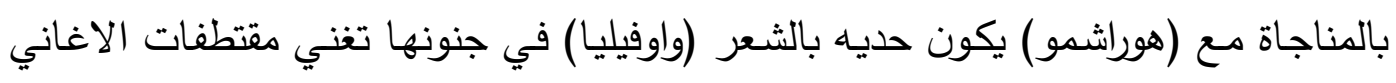

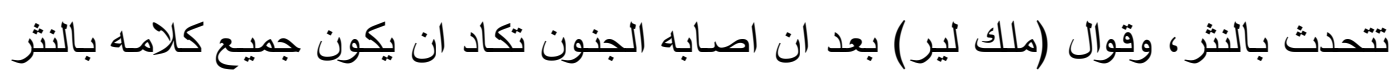

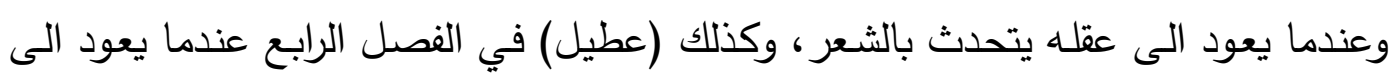

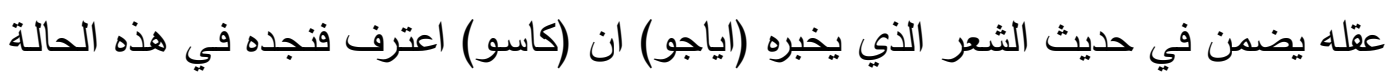
عشر اسطر من النثر ان في مسرحيات شكسبير تتنوع المفاهيم الاستعارية بين الحوارات

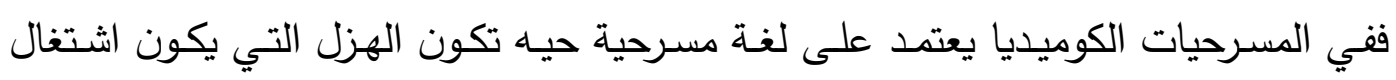

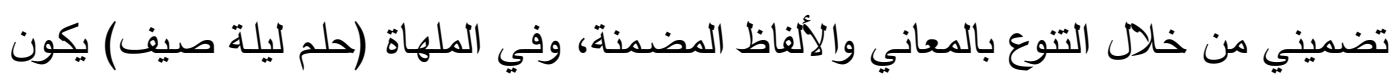

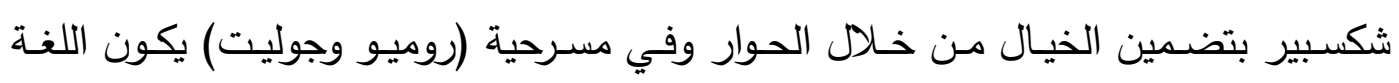
الحوار الرفيع بين الشعر والنثر ومسرحية هنري الخامس يكون داخل الجمل تضمينات لجمل ولئل

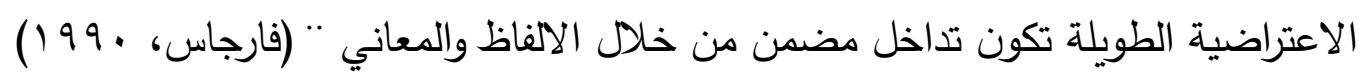

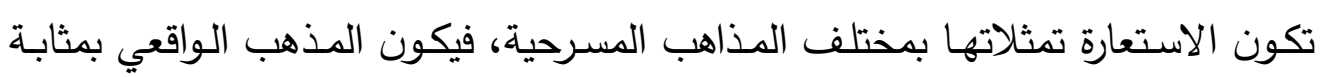
التعبير الكامل والصريح عن كل الصفاة الفردية، وهو بهذا يعكس بصورة محسوسـة تمثل كيان متثـابه للثيء الذي يكون الواقع، وتعبر اعمال المسرحية للنرويجي (هنريك ابسن)

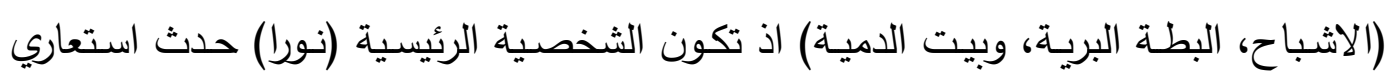

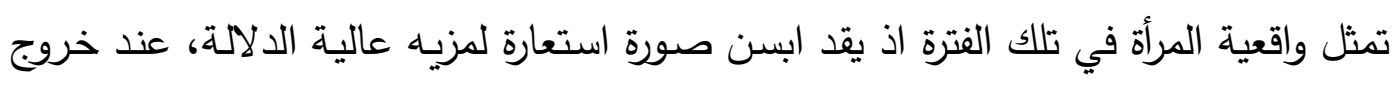

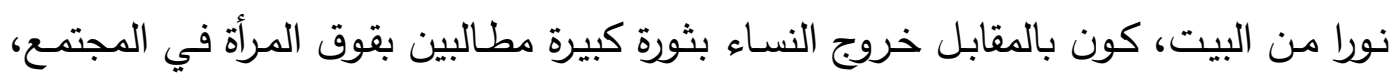
فالصورة الدلالية لنورا كون معنى استعاري صريح لان نشا عن اصل الصن الواقع للمرأة النرويجية

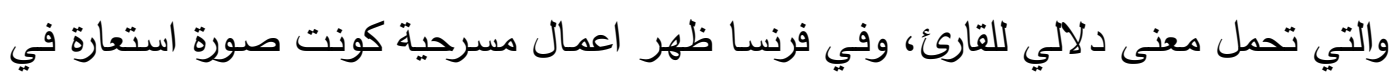

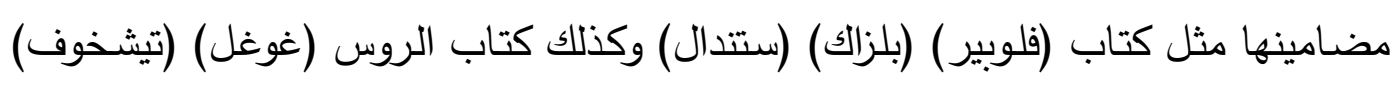
(وتلستوي) في اعمالهم تأثير بالبيئة والواقع تحمل استعارة دلالية عميقة. (خشبه، . 99 (1) )

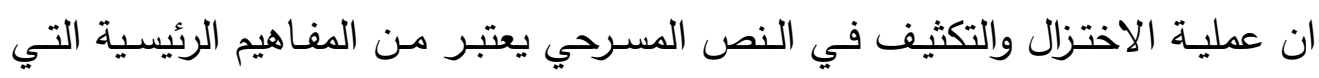

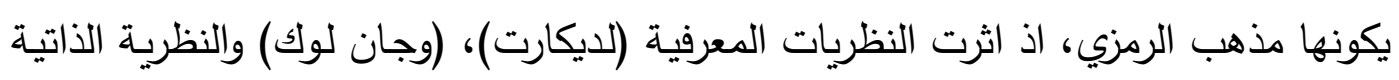

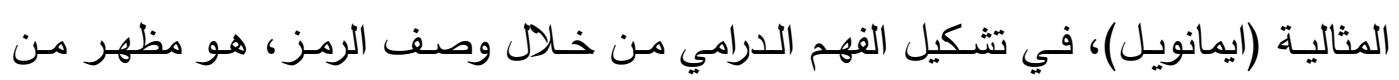

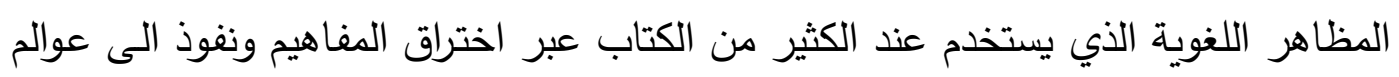

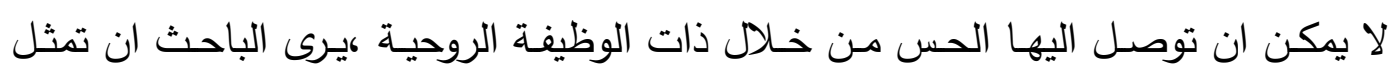

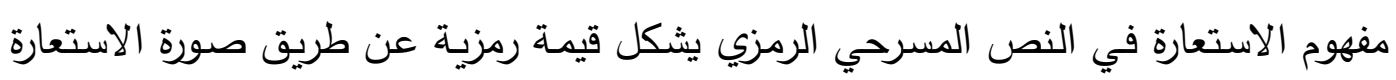

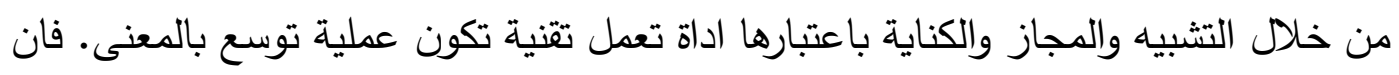




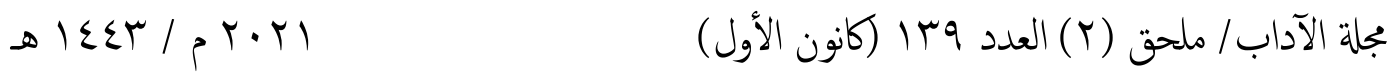

أبرز مـا كونتهـ الرمزيـة مـن مسرحيات (مسـرحية المتطفل، ومسـرحية العميـان، ومسـرحية

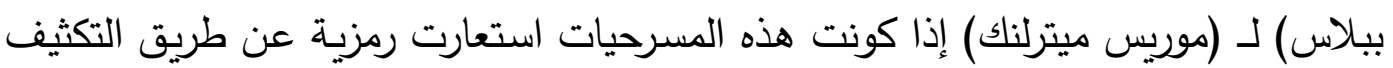

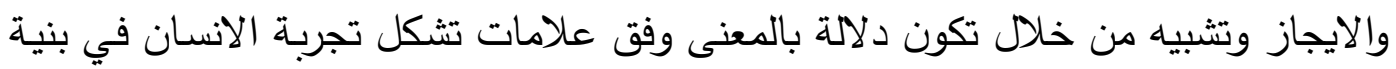

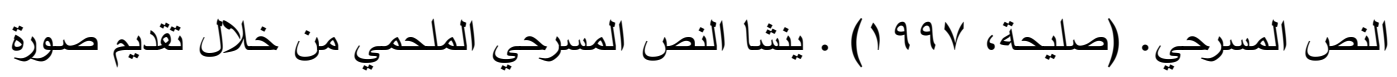

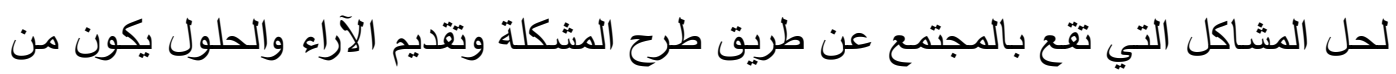

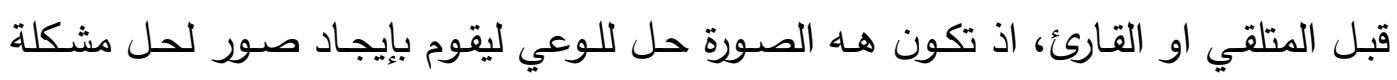
تصور البناء الفكري، ونرى في ذلك لنصوص مسرحية مثل مسرحية الام الثجاعة، ودائرة

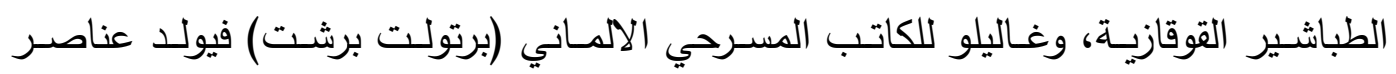

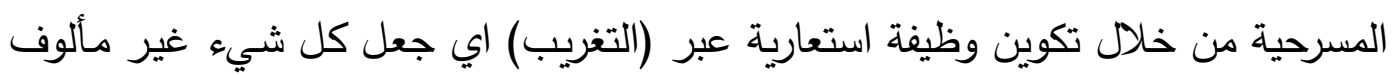

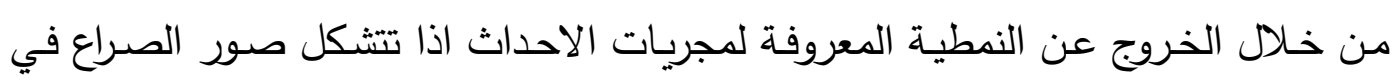

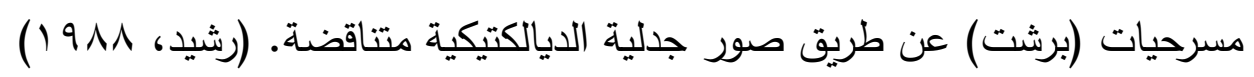
يكون النص المسرحي اللامعقول عبر عالم مبهه وغير تقليدي، هو عالم عالم يشعر الانسان

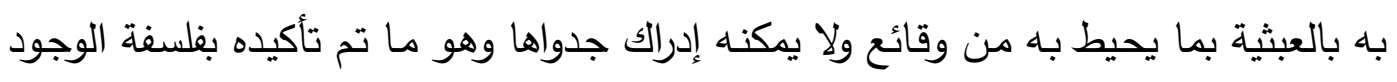

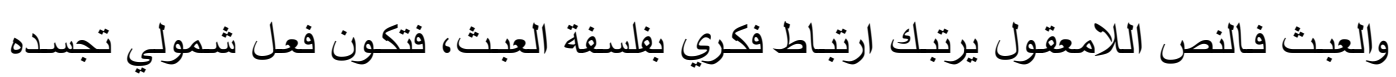

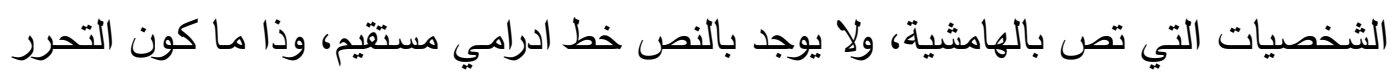

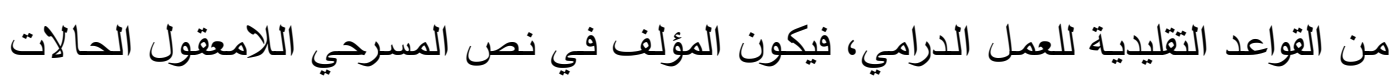

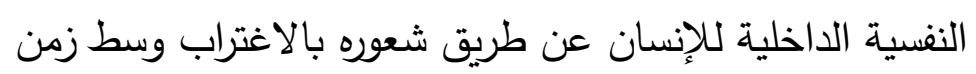

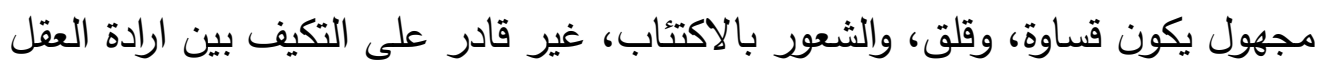

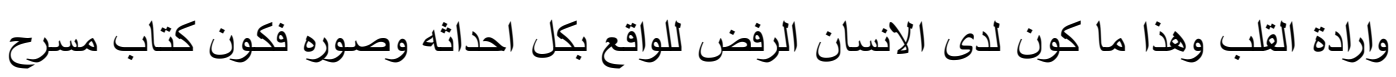

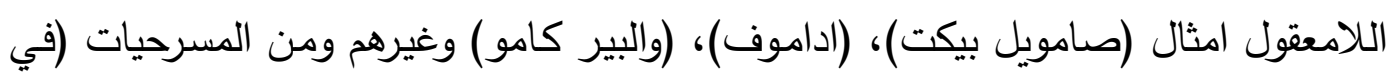

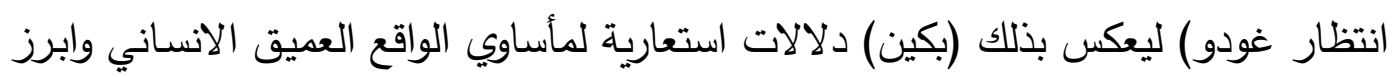

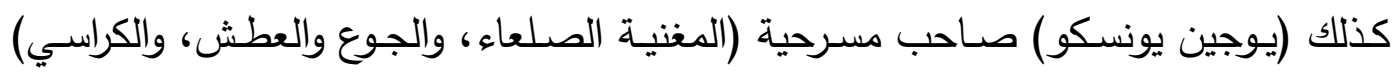

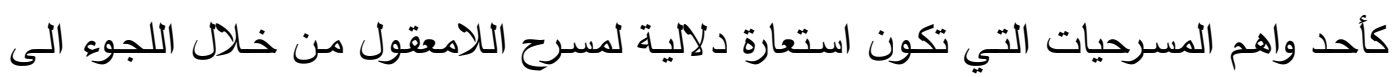

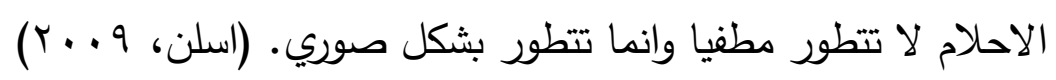
ما أسفر عنه الإطار النظري ا ـ تكون الاستعارة تثكيل لغوي مهم وعامل اثرا دلالكي داخل بنيـة اللغـة، باعتبارهـا اداة تعبيرية، ومصدر لتعدد المعنى.

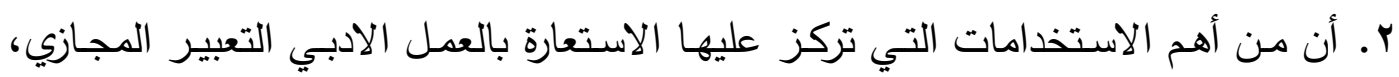

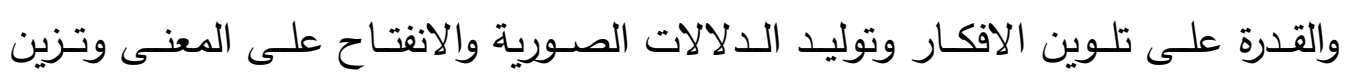
النصوص بقوة بلاغية مركزه 
r. تعد الاستعارة أحد وسائل الربط اللغوية للاشتغال الدلالي في النصوص المسرحية تعطي افاق واسع بتوليد معاني تجسد الحدث الدارئي

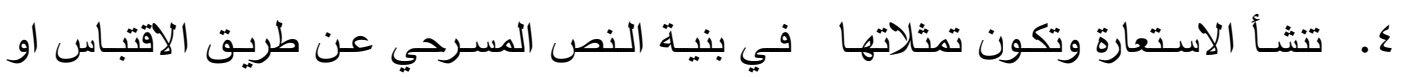
التشبيه او الكناية وغيرها.

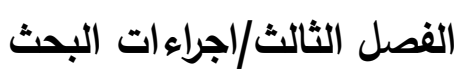
اولاً: مجتمع البحث

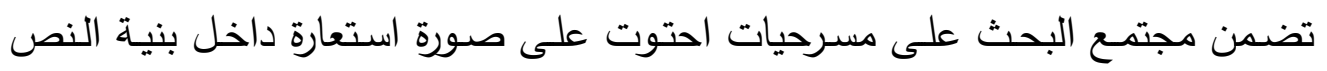

\begin{tabular}{|c|c|c|c|}
\hline \multicolumn{4}{|c|}{ تبت خلال فترة زمنية في العراق، وعرضت في المسرح الوطني. } \\
\hline التاريخ & المؤلف & اسم المسرحية & ت \\
\hline$r \cdot 1$. & عقيل مهاي & الحسين الان & 1 \\
\hline$r+11$ & مثال غازي & فصل من مسرحية مكبث & r \\
\hline 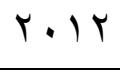 & سامي عبد الحميد & حروب & \\
\hline$r \cdot 1 T$ & علي عبد النبي الزيدي & يارب & \\
\hline
\end{tabular}

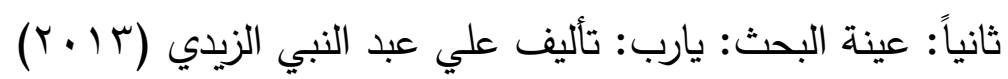

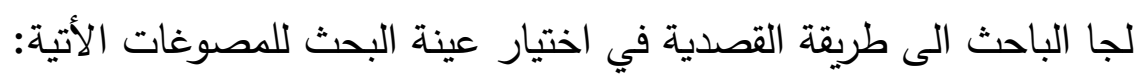
ا. تغطية النصوص الزمانية للبحث بشكل يساعد الذي يحقق اهداف الدراسة المتوخاة،

$$
\text { ويساعد على تعميم النتائج. }
$$

ثالثاً: اداة البحث: اعتمد الباحث على ما تم الاشارة اليه في الإطار النظري من مؤشرات.

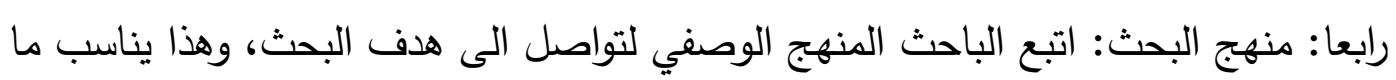
يرمي اليه البحث، واعتمد الباحث في التحليل عينة بحثه طريقة التحليل الوصفي. خامساً : تحليل نموذج العينة:

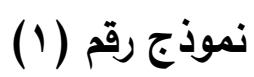

عنوان النص المسرحي (يارب) اسم المؤلف: علي عبد النبي الزيلي النياي

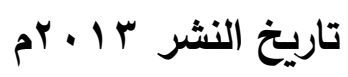
اولاً: قصة المسرحية:

شكلت المسرحية من خلال شخصيتين رئيستين متمثلة (موسى، الأم) تطرح شخصية (الام) المعاناة الامات المفجوعات في وطنٍ تسوده الحروب، والدمار ، والقتل. فتقرر الذهاب الى مكان، ويطلق عليه (الوادي المقدس) طوى للمناجاة الرب كما فعل نبي الله موسى (عاد (ع).

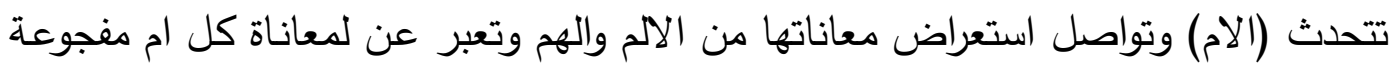


بولدها بوصفها تمثل الواقع، اذ تلتقي (الام) بـ(موسى) الذي ارسله الرب للتفاوض مع الام

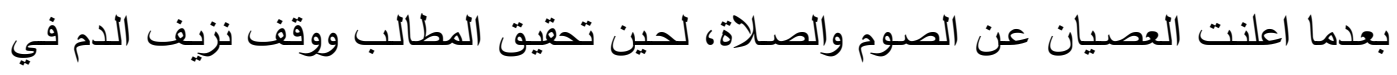

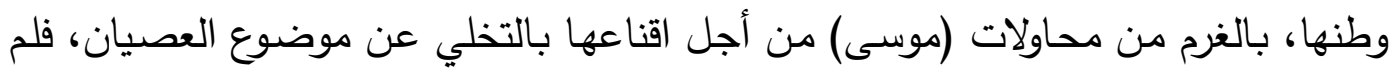

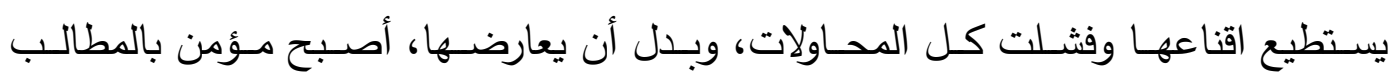
المشروعة فأصبح جزء من العصيان في نهاية المطاف. تحليل العينية:

كون النص المسرحي انواع صورية استعارية تكون بعد دلالي للمعنى المكون للعمل الفني ففي مسرحية يارب تنشا الثخصيات صور استعارية فشخصية (الام) في الخمسينيات

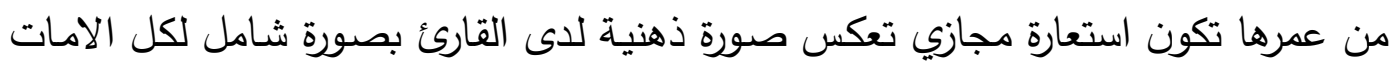

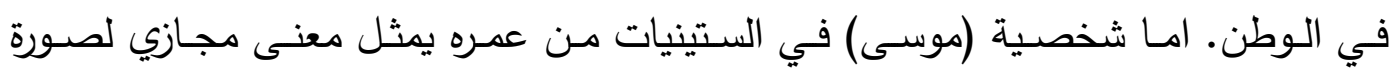
استعارية تصريحية لنبي جاء لكي يتفاوض، وكون المكان صورة دلالية استعارية (الوادي

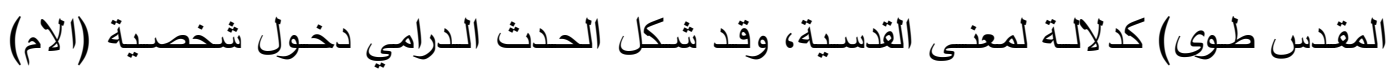
الوادي المقدس استعارة دلاليـة لمعنى طلب الدعاء والعون وكذلك صورة حلف حلث حضور شخصية (موسى) للوادي المقدس استعارة تثبيهيه لمعنى الاله.

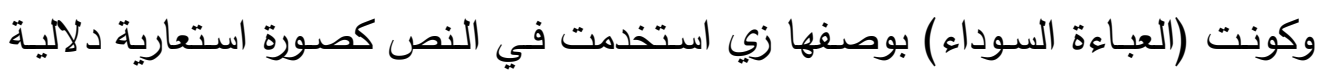

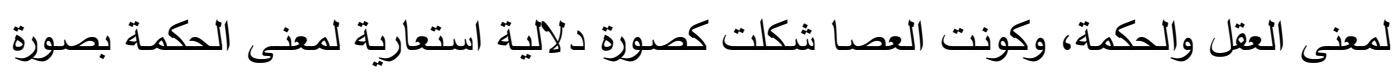

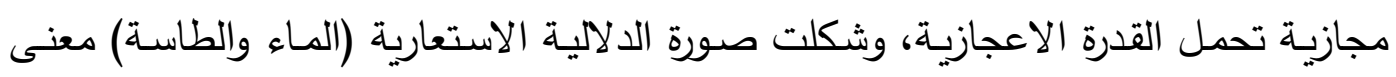

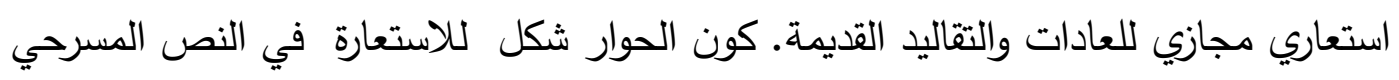
عنصراً لغوياً رئيساً من عناصر الانتاجية للمعنى الموسع وانتاج عبر الفعل الابداعي معاني

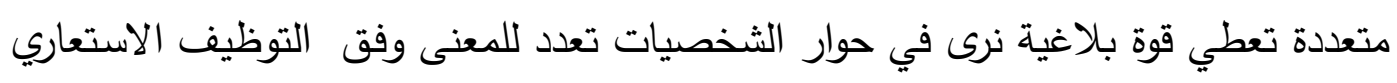
الذي جاء على لسان شخصية (الام) وهو استعارة اقتباسي بشكل مباشر من فئ آيات القران

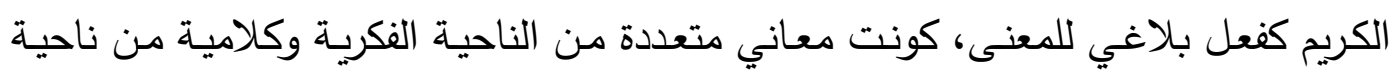

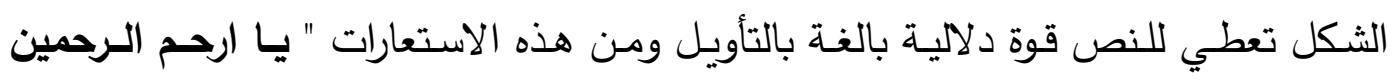

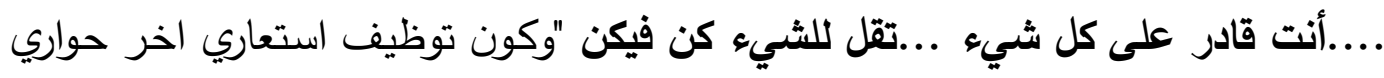

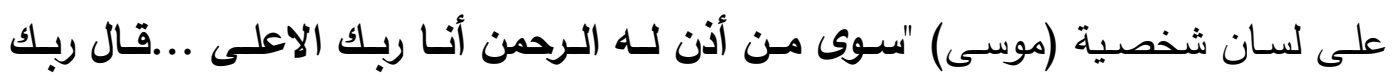

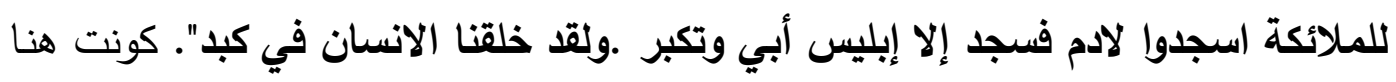

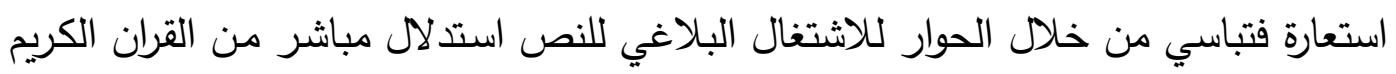

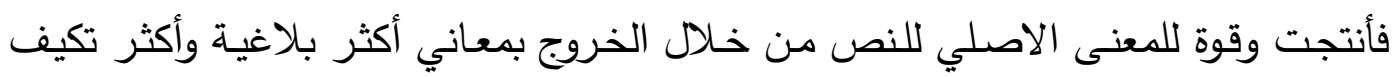
وايجاز ضمن سياقات اللغة للنص. ونرى في حوار على لسان شخصية (الام) اقتباس من فن فئن

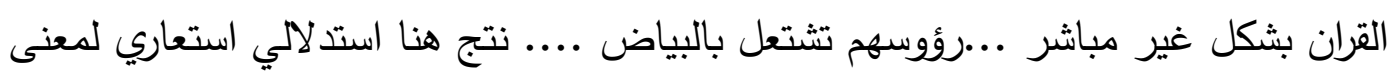




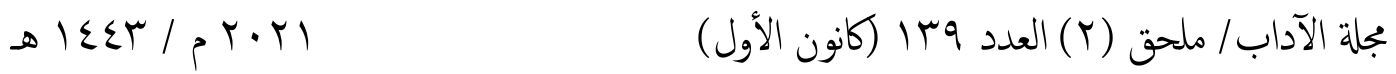

لا يه من القران الكريم (واشتعل الراس شيباً) اعطى لمعنى النص بلاغي موسـع كتعبير

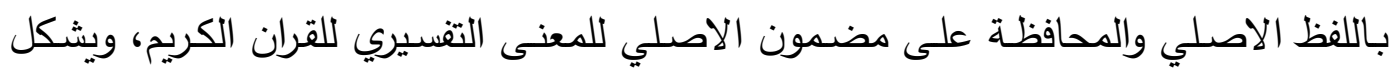

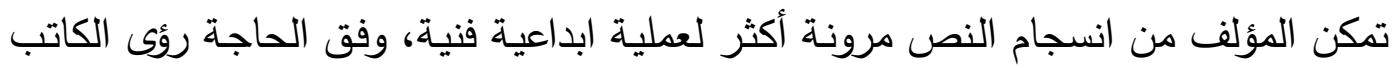

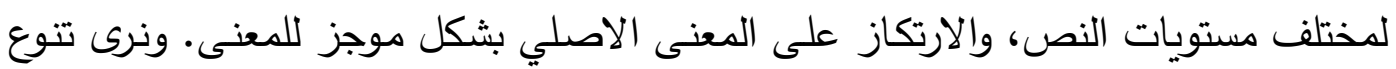

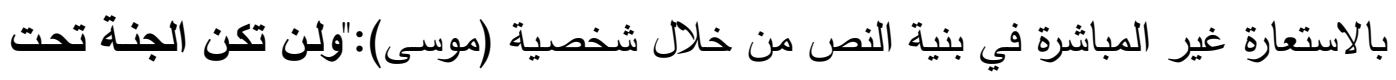

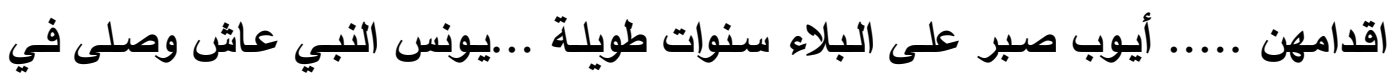
جوف الحوت ...عيسى صلبوه بأبشع ما يكون الصلب.. يعقوب الذي ابيض عيناه وكان كظيم ...الأنهار تجري مـن تحت اقدامهم حور العين.. الجنـة تجري تحتها الانهار

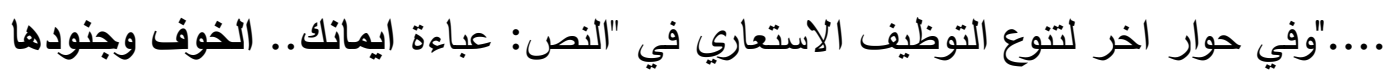

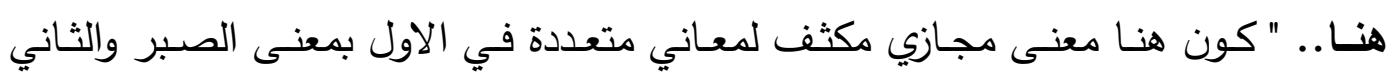
كصورة استعارية تخيلية لشخصية (فرعون) الحقيقية بالقران الكريم. وفي حوار اخر على لسان شخصية (موسى) "ربي اوقف هذا السواد... "بمعنى استعارة

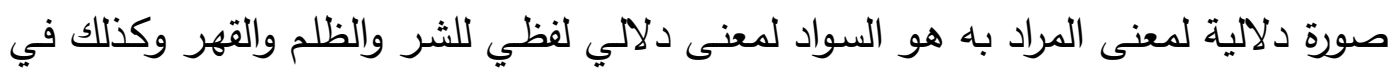

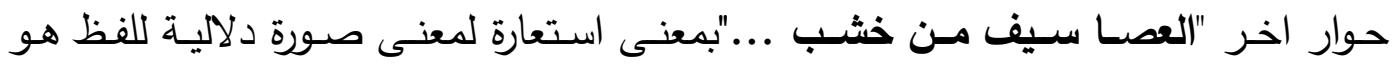

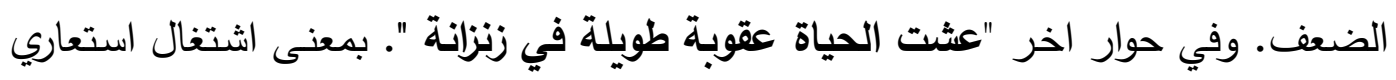

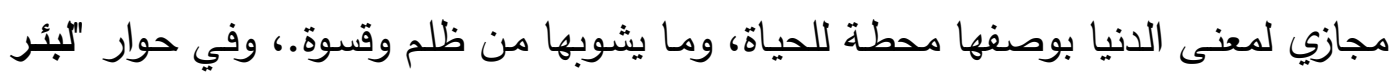
يوسف أهون بكثير من الظلمة ...بمعنى استعاري اقتباس لصورة قلت الالم والهوان للبئر من شدة وقسوة الظلم والقتل في الوطن اعطت توظيف مجازي لبنية النص ل لمعنى بلاغي

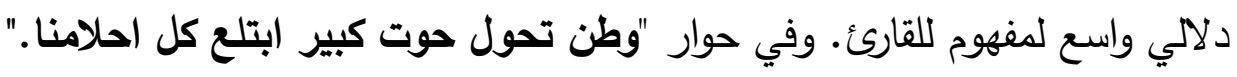

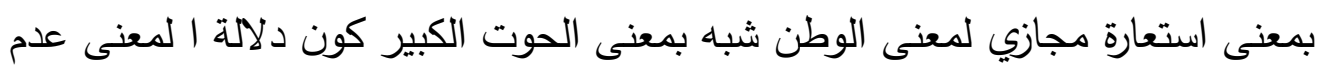

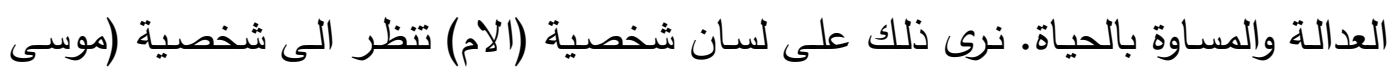

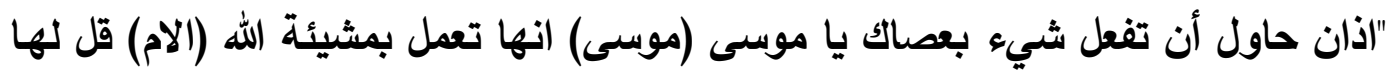

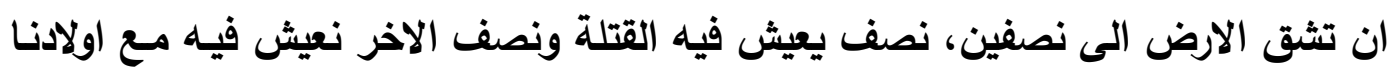

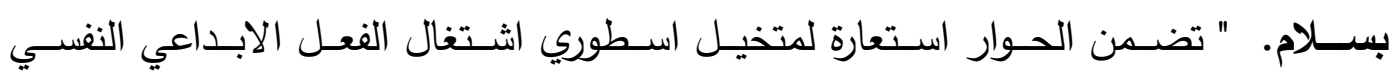

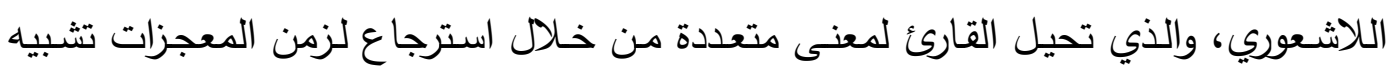

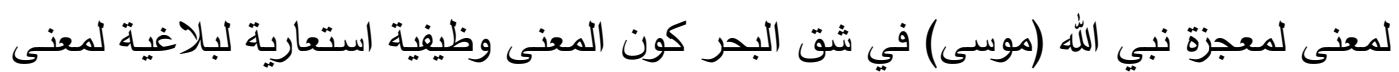
عند المؤلف. 
1. ساهمت الاستعارة من خلال تمثلاتها الدلالية في نص المسرحي، الى تكوين اداة مهمة

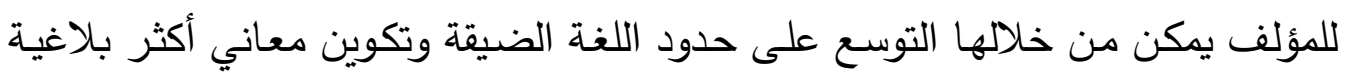
من خلال التكثيف والاقتباس والإيجاز ، وكما في نماذج العينة المختارة..

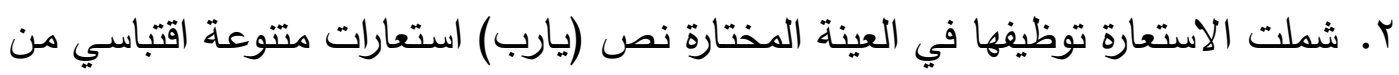
القران الكريم بشكل مباشر او غير مباشر ، بالاعتماد على دلالة المعنى واللفظ.

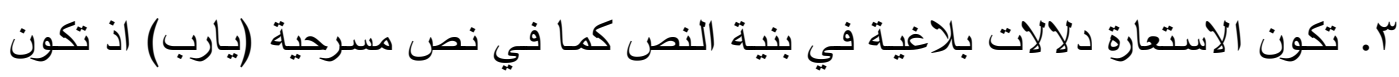

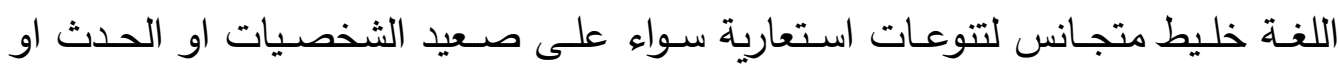
المكان والحوار كون افاق بلاغية فنية عمقت المعنى.

الاستنتاجات:

ا. اعتبرت الاستعارة تقنية جمالية وفنية يلجئ لها الكاتب، للارتكاز على مفاهيم خارجية

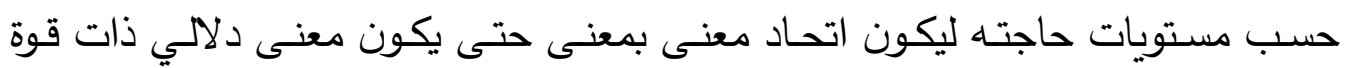
بلاغية وتأويلية تعزز المفهوم العميق لدى القارئ.

r. عبرت الاستعارة الحدود البلاغية وعدم اقتصارها على نوع محدد من الفنون الادبي، بل لعيل

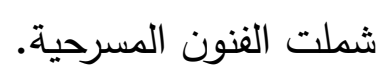

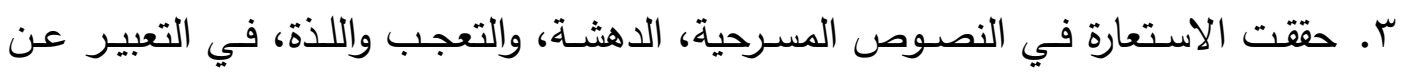

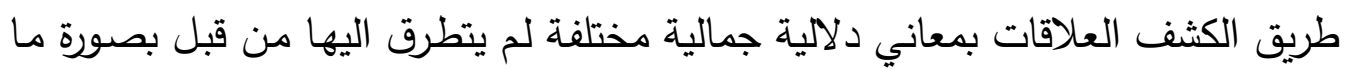

$$
\text { لوفه في نص المسرحي. }
$$

المصادر والمراجع

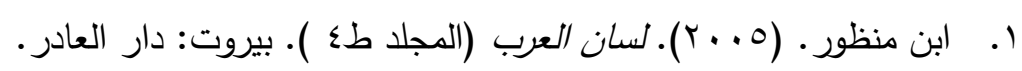

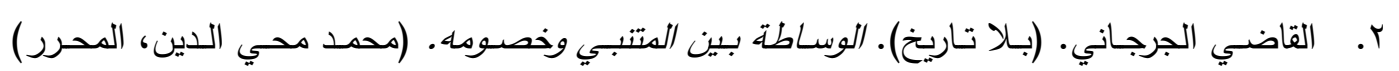
القاهرة: دار الجيل.

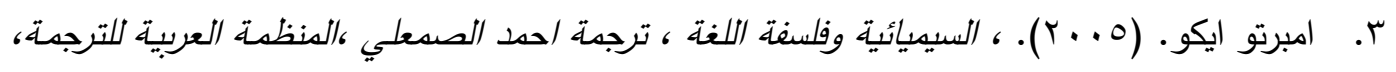

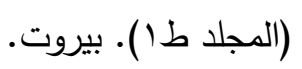
ع. ترينس هوكس. (T ( ب). الاستعارة ، ترجمة عمرو زكريا عبد الله ، مراجعة ، محد بربري ، المركز

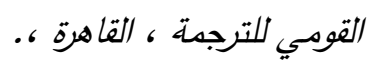

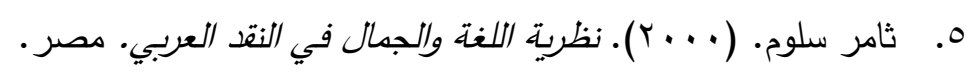
7.

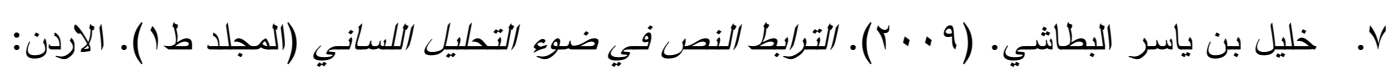
الجديدة للنشر والتوزيع.

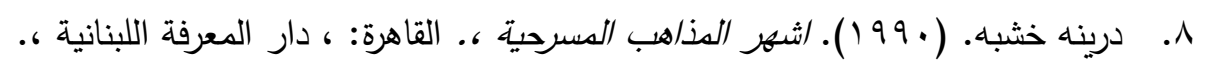




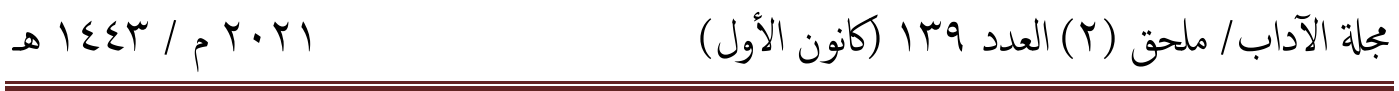

9. شلدون تشيني. (ra19 ). تاريخ المسرح في ثلاث الالف سنة. (ترجمة ، درينه خشبة، المترجمون) القاهرة: موسسة المصرية العامة.

• 1. صالح بن هادي رمضان. (ـ99 (1). ، النظرية الادركية في درس البلاغي الاستعارة ،. دار الدراسات البلاغية ، النشر وتوزيع الواقع المامول ، مصري مان.

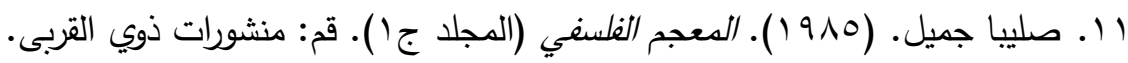

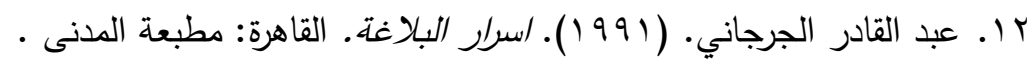

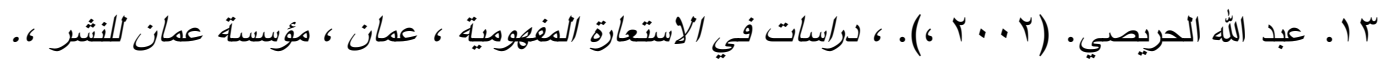

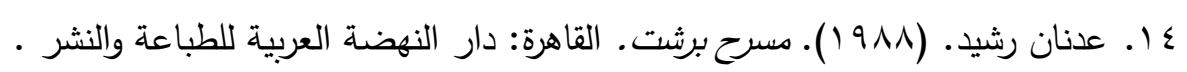

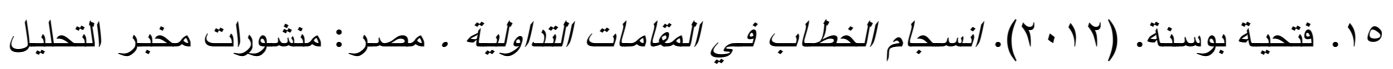

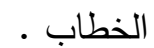
1 1. لويس فارجاس. ( • (199). المشهر الى فن المسرح. القاهرة: مهرجان القراءة .

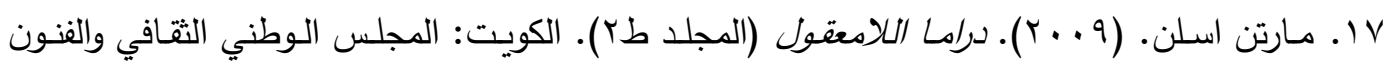
والادب.

1 ا. محمد عبد فيحان. (r . . ץ). تطور الاساليب الثعرية في اللغتة الدرامية العالمية. محمد عبد فيحان ،

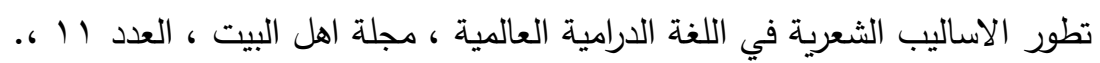

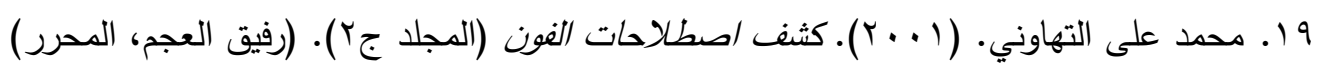

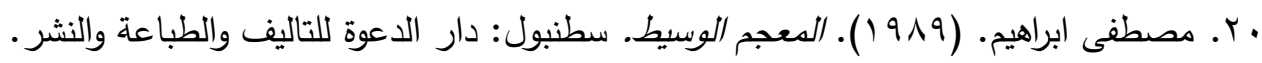

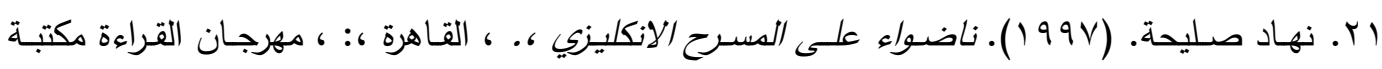

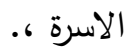
ب Y. : احمد عبد السيد الحاوي. (، 9 ( I) ). فن الاستعاة.

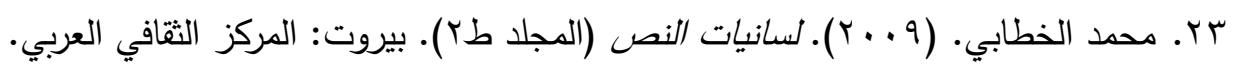

\section{Sources and References}

- Abdul Qadir Al-Jurjani. (1991). The Secrets of Rhetoric. Cairo: Al-Madani Press.

- Abdullah Al-Harissi. (2002). Studies in Conceptual Metaphor, Amman, Amman Publishing Institution.

- Adnan Rashid. (1988). Brecht Theatre. Cairo: Dar Al-Nahdha Al-Arabiya for Printing and Publishing.

- Drina Khashaba. (1990). The Most Famous Theatrical Schools. Cairo: The Lebanese Knowledge House.

- Fethiya, Bosinna. (2012). Harmony of Discourse in Deliberative Maqamats. Egypt: Discourse Analysis Lab Publications.

- Ibn Manzur. (2005). Lisan Al Arab (Volume 4). Beirut: Dar Al-Ader.

- Jameel Hamdaoui. (No date). Lectures in the Text Linguistics. Copyright reserved to the author.

- Khalil bin Yasir Al-Batashi. (2009). Text coherence in the Light of Linguistic Analysis (Volume 1). Jordan: Al-Jadida for Publishing and Distribution.

- Louis Vargas. (1990). The Scene to the Art of Theatre. Cairo: Reading Festival. 


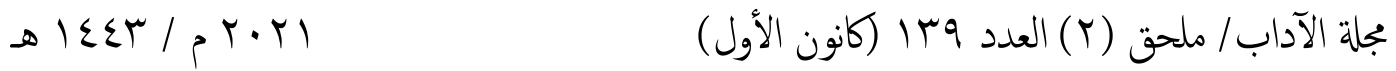

- Martin Eslen (2009); Drama of the Unreasonable (Volume 2). Kuwait: The National Council for Culture, Arts and Literature.

- Muhammad Abed Fayhan. (2003). The Development of Poetic Styles in the International Drama Language. Muhammad Abd Fayhan, The Evolution of Poetic Styles in the International Dramatic Language, Ahl Ul-Bayt Magazine, No. 11.

- Nihad Saliha. (1997). Lights on the English Theatre, Cairo, Family Library, Reading Festival.

- Saleh bin Hadi Ramadan. (1994). Perceptual Theory in the Rhetorical Lesson, Metaphor. House of Rhetorical Studies, Published and Distributed by Al-Wakhi and Al Maamoul, Egypt.

- See: Ahmed Abdel-Sayed Al-Hawi. (1979). The Art of Metaphor.

- See: Ahmed Abdel-Sayed Al-Hawi. (1979). The Art of Metaphor.

- See; Mohammed Al-Khattabi. (2009). Linguistics of the Text

- Sheldon Cheney. (1983); The History of Theater in Three Thousand Years. (Translated by Drina Khashaba, Translators) Cairo: The Egyptian Public Institution.

- Terence Hooks. (2016). Metaphor, translated by Omar Zakaria Abdullah, revised by Mohamed Barbary, the National Center for Translation, Cairo.

- Thamir Salloum. (2000). The Theory of Language and Beauty in Arabic Criticism, Egypt.

- The Judge Al-Jurjani. (No date). Mediation between Al-Mutanabbi and his Opponents. (Mohamed Mohi Eldin, editor) Cairo: Dar Al-Jeel.

- Umberto Echo. (2005). Semiotics and the Philosophy of Language, translated by Ahmed Al-Sameli, The Arab Organization for Translation, (Volume 1). Beirut. 